\title{
PENYELESAIAN PERSAMAAN NONLINIER ORDE-TINGGI UNTUK AKAR BERGANDA
}

\author{
Mohammad Jamhuri \\ Jurusan Matematika, Fakultas Sains dan Teknologi, \\ Universitas Islam Negeri Maulana Malik Ibrahim Malang \\ j4m3sh@gmail.com
}

\begin{abstract}
Abstrak
Dalam paper ini dikembangkan sebuah metode Orde-Empat untuk mencari akar berganda dari persamaan nonlinier. Metode tersebut di dasarkan pada metode Orde-Lima dari Jarrat (untuk akar-akar sederhana) yang hanya memerlukan satu perhitungan fungsi dan tiga kali perhitungan turunan. Efisiensi informasi dari metode tersebut sama dengan metode-metode dengan orde yang lebih rendah. Untuk kasus-kasus akar berganda, telah ditemukan metode-metode yang hanya memerlukan satu kali perhitungan turunan. Sehingga metode-metode tersebut lebih efisien jika dibandingkan dengan metode-metode lainnya.
\end{abstract}

Kata kunci: akar berganda, Orde-tinggi, Persamaan Nonlinier.

\section{Pendahuluan}

Ada berbagai macam literature untuk masalah penyelesaian persamaan nonlinier dan sistem persamaan nonlinier. Lihat pada contoh Ostrowski (1960), Traub (1964), Neta (1983) dan pada referensi-referensi yang lainnya. Dalam penelitian ini akan dikembangkan sebuah metode titik-tetap Orde-tinggi untuk penyelesaian akar berganda. sebenarnya terdapat banyak metode yang dapat digunakan untuk mencari akar $\xi$ dari $m$ persamaan nonlinier $f(x)=0$, lihat Neta (1983). Metode Newton hanya salah satu metode orde-satu kecuali yang dimodifikasi sehingga menjadi orde-dua tingkat konvergensinya, lihat Rall (1996) atau Schroder (1996). Untuk memodifikasi diperlukan pengetahuan tentang multiplicity. Traub (1964) telah menyarankan penggunaan sebuah metode untuk $f^{(m)}(x)$ atau $g(x)=\frac{f(x)}{f^{\prime}(x)}$, beberapa metode tersebut memerlukan turunan yang libih tinggi dari pada yang digunakan untuk masalah akar sederhana yang hanya memiliki satu akar. Sehingga yang pertama dari metode-metode tersebut adalah mengetahui multiplicity $m$. Dalam beberapa hal, terdapat metode orde-tinggi yang dikembangkan oleh Hamsen dan Patrick (1977), Victory dan Neta (1987), dan Dong (1987). Karena secara umum tidak dapat diketahui multiplicity-nya, Traub (1964) menyarankan sebuah jalan untuk mengaproksimasinya pada saat iterasi.

Sebagai contoh, metode Newton yang dimodifikasi dengan tingkat konvergensi kuadratik adalah

$$
x_{n+1}=x_{n}-m \frac{f_{n}}{f_{n}^{\prime}}
$$

Dan metode Halley (1964) dengan tingkat konvergensi kubik adalah

$$
x_{n+1}=x_{n}-\frac{f_{n}}{\frac{m+1}{2 m} f_{n}^{\prime}-\frac{f_{n} f_{n}^{\prime \prime}}{2 f_{n}^{\prime}}}
$$

Dimana $f_{n}^{(i)}$ adalah kependekan dari $f_{x_{n}}^{(i)}$. Metode orde-tiga lainnya telah dikembangkan oleh Victory dan Neta (1987) yang didasarkan metode orde-empat-nya King (1973) untuk akar-akar sederhana. 
Dimana

$$
\begin{gathered}
w_{n}=x_{n}-\frac{f_{n}}{f_{n}^{\prime}} \\
x_{n+1}=w_{n}-\frac{f\left(w_{n}\right)}{f_{n}^{\prime}} \frac{f_{n}+A f\left(w_{n}\right)}{f_{n}+B f\left(w_{n}\right)}
\end{gathered}
$$

Dan

$$
\begin{gathered}
A=\mu^{2 m}-\mu^{m+1} \\
\mu^{m}(m-2)(m-1)+1
\end{gathered}
$$

$$
\mu=\frac{m}{m-1}
$$

Sebelumnya, dua metode orde-tiga telah dikembangkan oleh Dong (1987), keduanya memerlukan informasi yang sama dan keduanya juga didasarkan pada keluarga metodemetode orde-empat (untuk akar-akar sederhana) oleh Jarrat (1966):

$$
\begin{aligned}
& x_{n+1}=x_{n}-u_{n}-\frac{f\left(x_{n}\right)}{\left(\frac{m}{m-1}\right)^{m+1} f^{\prime}\left(x_{n}-u_{n}\right)+\frac{m-m^{2}-1}{(m-1)^{2}} f^{\prime}\left(x_{n}\right)} \\
& x_{n+1}=x_{n}-\frac{m}{m+1} u_{n}-\frac{\frac{m}{m+1} f\left(x_{n}\right)}{\left(1+\frac{1}{m}\right)^{m} f^{\prime}\left(x_{n}-\frac{m}{m+1} u_{n}\right)-f^{\prime}\left(x_{n}\right)}
\end{aligned}
$$

Dimana $u_{n}=\frac{f\left(x_{n}\right)}{f^{\prime}\left(x_{n}\right)}$.

Langkah awal dari metode yang akan dibentuk disini adalah metode Jarrat (1996) yang diberikan

$$
x_{n+1}=x_{n}-\frac{f\left(x_{n}\right)}{a_{1} f^{\prime}\left(x_{n}\right)+a_{2} f^{\prime}\left(y_{n}\right)+a_{3} f^{\prime}\left(\eta_{n}\right)}
$$

Dimana $u_{n}$ seperti diatas dan

$$
\begin{gathered}
y_{n}=x_{n}-a u_{n} \\
v_{n}=\frac{f\left(x_{n}\right)}{f^{\prime}\left(y_{n}\right)} \\
\eta_{n}=x_{n}-b u_{n}-c v_{n}
\end{gathered}
$$

Jarrat (1996) telah menunjukkan bahwa metode ini (untuk akar sederhana) adalah dari orde-lima jika parameter-parameter yang dipilih adalah sebagai berikut:

$$
a=1, \quad b=\frac{1}{8}, \quad c=\frac{3}{8}, \quad a_{1}=a_{2}=\frac{1}{6}, \quad a_{3}=\frac{2}{3}
$$

Metode tersebut memerlukan satu fungsi-dan tiga turunan-untuk setiap langkah perhitungan. Sehingga efisiensi informasi adalah 1.25 (Traub, 1964). Karena Jarrat (1996) tidak memberikan konstanta error asymptotic-nya, maka digunakan Redfern (1994) untuk memperolehnya,

$$
\frac{1}{24} A_{5}+\frac{1}{2} A_{4} A_{2}-\frac{1}{4} A_{3}^{2}+\frac{1}{8} A_{2}^{2} A_{3}+A_{2}^{4}
$$

Dimana $A_{i}$ diberikan oleh (14) dengan $m=1$.

\section{Skema Baru untuk Orde-Tinggi}

Untuk memaksimalkan orde-konvergensi untuk sebuah akar $\xi$ dengan perkalian $m$ harus ditentukan enam parameter $a, b, c, a_{1}, a_{2}, a_{-} 3$. Misalkan $e_{n}, \hat{e}_{n}, \epsilon_{n}$ adalah error pada untuk iterasi ke- $n$, yaitu:

$$
\begin{aligned}
& e_{n}=x_{n}-\xi \\
& \hat{e}_{n}=y_{n}-\xi
\end{aligned}
$$




$$
\epsilon=\eta_{n}-\xi
$$

Jika $f\left(x_{n}\right)$ dan $f^{\prime}\left(x_{n}\right)$ di expansi menggunakan deret Taylor (setelah dipotong sampai orde ke- $N, N>m$ ) diperoleh

$$
\begin{aligned}
f\left(x_{n}\right)=f\left(x_{n}-\xi+\xi\right)=f\left(\xi+e_{n}\right) & \\
= & \frac{f^{(m)}(\xi)}{m !}\left(e_{n}^{m}+\sum_{i=m+1}^{N} A_{i} e_{n}^{i}\right)
\end{aligned}
$$

atau

dimana

$$
f\left(x_{n}\right)=\frac{f^{(m)}(\xi)}{m !} e_{n}^{m}\left(1+\sum_{i=m+1}^{N} B_{i-m} e_{n}^{i-m}\right)
$$

Untuk mengekspansi $f^{\prime}\left(y_{n}\right)$ dan $f^{\prime}\left(\eta_{n}\right)$ digunakan manipulasi symbolic, seperti Redfern (1994), diperoleh

$$
\begin{aligned}
f^{\prime}\left(y_{n}\right) & =\frac{f^{(m)}(\xi)}{(m-1) !} \hat{e}_{n}^{m-1}\left(1+\frac{m+1}{m} B_{1} \hat{e}_{n}+\frac{m+2}{m} B_{2} \hat{e}_{n}^{2}+\cdots\right) \\
\hat{e}_{n} & =e_{n}-a u_{n} \\
& =\left(1-\frac{a}{m}\right) e_{n}+\frac{a}{m^{2}} B_{1} e_{n}^{2}+\left[\frac{2 a}{m^{2}} B_{2}-\frac{a(m+1)}{m^{3}} B_{1}^{2}\right] e_{n}^{3}+\cdots \\
& =\left(1-\frac{a}{m}\right) e_{n}+\frac{a}{m^{2}} B_{1} e_{n}^{2}+\left[\frac{2 a}{m^{2}} B_{2}-\frac{a(m+1)}{m^{3}} B_{1}^{2}\right] e_{n}^{3}+\cdots \\
& =\frac{1}{2} e_{n}+\frac{1}{2 m} B_{1} e_{n}^{2}+\frac{1}{m}\left[B_{2}-\frac{m+1}{2 m} B_{1}^{2}\right] e_{n}^{3}+\cdots
\end{aligned}
$$

Dimana untuk memudahkan dipilih

sehingga

$$
a=\frac{m}{2}
$$

dimana

$$
f^{\prime}\left(y_{n}\right)=\frac{f^{(m)}(\xi)}{(m-1) !} e_{n}^{m-1}\left(c_{0}+c_{1} e_{n}+c_{2} e_{n}^{2}+c_{3} e_{n}^{3}+\cdots\right)
$$

$$
\begin{gathered}
c_{0}=2^{1-m} \\
c_{1}=\frac{3 m-1}{m} 2^{-m} B_{1} \\
c_{2}=\left[\frac{4-2 m}{m^{2}} B_{1}^{2}+\frac{3(3 m-2)}{2 m} B_{2}\right] 2^{-m} \\
c_{3}=\left[\frac{25 m-21}{4 m} B_{3}+\frac{m^{2}-21 m+34}{2 m^{2}} B_{1} B_{2}\right. \\
\left.-\frac{m^{3}-12 m^{2}-13 m+48}{6 m^{3}} B_{1}^{3}\right] 2^{-m}
\end{gathered}
$$

Error-nya diberikan oleh 


$$
\begin{gathered}
\epsilon_{n}=e_{n}-b u_{n}-c v_{n}=\lambda e_{n}+\frac{2 b+\hat{c}(m-1)}{2 m^{2}} B_{1} e_{n}^{2} \\
+\left[\frac{8 b+(5 m-6) \hat{c}}{4 m^{2}} B_{2}-\frac{4 b(m+1)-\left(3 m^{2}-7\right) \hat{c}}{4 m^{3}} B_{1}^{2}\right] e_{n}^{3}+\cdots
\end{gathered}
$$

Dimana

$$
\begin{gathered}
\hat{c}=2^{m-1} c \\
\lambda=1-\frac{b+\hat{c}}{m}
\end{gathered}
$$

Berikutnya ekspansi $f^{\prime}\left(\eta_{n}\right)$ dalam bentuk $e_{n}$

$$
\begin{aligned}
& f^{\prime}\left(\eta_{n}\right)=\frac{f^{(m)}(\xi)}{(m-1) !} \epsilon_{n}^{m-1}\left(1+\frac{m+1}{m} B_{1} \epsilon_{n}+\frac{m+2}{m} B_{2} \epsilon_{n}^{2}+\cdots\right) \\
& =\frac{f^{(m)}(\xi)}{(m-1) !} e_{n}^{m+1}\left(d_{0}+d_{1} e_{n}+d_{2} e_{n}^{2}+\cdots\right)
\end{aligned}
$$

dimana

$$
\begin{gathered}
d_{0}=\lambda^{m-1} \\
d_{1}=\frac{\lambda^{m-2} B_{1}}{m^{3}}\left\{\left(m^{2}+b^{2}\right)(m+1)-b m(m+3)+(m+1) \hat{c}^{2}\right. \\
\left.+\left[2 b(m+1)-m \frac{\left.m^{2}-6 m-3\right]}{2}\right] \hat{c}\right\} \\
d_{2}=-\frac{\lambda^{m-3}}{32 m^{5}} B_{1}^{2}\left[\alpha_{1} b+\beta_{1} \hat{c}+\gamma_{1} \hat{c}+\delta_{1} \hat{c}^{3}\right] \\
+\frac{\lambda^{m-3}}{m^{5}} B_{2}\left[\alpha_{2}+\beta_{2} \hat{c}+\gamma_{2} \hat{c}^{2}+\delta_{2} \hat{c}^{3}+\gamma_{3} \hat{c}^{4}\right]
\end{gathered}
$$

Dimana

$$
\begin{gathered}
\alpha_{1}=16\left[2 m(m+1) b^{2}-m^{2}(m-7) b+2 m^{2}(m+1)\right] \\
\beta_{1}=8 m\left[6 b^{2}(m+1)(m+3)+b\left(m^{3}-15 m^{2}-m-1\right)\right. \\
\left.-m(m-1)\left(m^{2}-2 m-7\right)\right] \\
\gamma_{1}=4\left[8 b m^{2}(m+1)+m(m-1)\left(m^{3}-6 m^{2}-3 m-16\right)\right. \\
\left.+4 m^{2}(m-1)\right] \\
\delta_{1}=16 m^{2}(m-1) \\
\alpha_{2}=32\left[b^{4}(m+2)-4 b^{3} m^{2}+2 b^{2} m(m+4)(2 m-1)\right. \\
\left.-2 b m^{3}(m+5)+m^{5}(m+2)\right] \\
\beta_{2}=8\left[16 b^{3}(m+2)-48 b^{2} m(m+2)-b m^{2}\left(5 m^{2}-51 m-98\right)\right. \\
\left.+m^{3}\left(5 m^{2}-27 m-26\right)\right] \\
\gamma_{2}=8\left[24 b^{2}(m+2)-48 b m(m+2)-m^{2}\left(5 m^{2}-35 m-42\right)\right] \\
\delta_{2}=128[b(m+2)-m(m+1)] \\
\gamma_{3}=32(m+2)
\end{gathered}
$$

Berikutnya substitusikan (13), (15), (19) dan (23) kedalam (8) dan expansi kuasi $\frac{f_{n}}{a_{1} f^{\prime}\left(x_{n}\right)+a_{2} f^{\prime}\left(y_{n}\right)+a_{3} f^{\prime}\left(\eta_{n}\right)}$ menggunakan deret Taylor, sehingga diperoleh

$$
\begin{gathered}
e_{n+1}=e_{n}-\frac{f_{n}}{a_{1} f^{\prime}\left(x_{n}\right)+a_{2} f^{\prime}\left(y_{n}\right)+a_{3} f^{\prime}\left(\eta_{n}\right)} \\
=C_{1}^{1} e_{n}+C_{2}^{1} B_{1} e_{n}^{2}+\left(C_{3}^{1} B_{1}^{2}+C_{3}^{2} B_{2}\right) e_{n}^{3}+\left(C_{4}^{1} B_{1}^{3}+C_{4}^{2} B_{1} B_{2}+\right. \\
\left.C_{4}^{3} B_{3}\right) e_{n}^{4}+\cdots
\end{gathered}
$$


Dimana koefisien $C_{i}^{j}$ tergantung pada parameter-parameter $b, c, a_{1}, a_{2}, a_{3}$. Kelima parameter tersebut dapat digunakan untuk menghilangkan koefisien $e_{n}, e_{n}^{2}, e_{n}^{3}$ dan $e_{n}^{4}$. Sehingga orde dari metode tersebut adalah $p=4$. Sebenarnya, kecuali untuk $m=2$, digunakan $b=a=\frac{m}{2}$ dan sehingga hanya 4 parameter yang di gunakan. Ini merupakan syarat perlu untuk memperoleh metode orde-empat.

TABEL 1. Hasil dari contoh 2

\begin{tabular}{ccccc}
\hline$n$ & $x$ & $f$ & $x$ & $f$ \\
\hline 0 & 0.8 & 0.1296 & 0.6 & 0.4096 \\
1 & 1.00074058 & $0.21954564(-5)$ & 1.02772227 & $0.31600247(-2)$ \\
2 & & & 1.00000014 & $0.750396(-13)$ \\
\hline
\end{tabular}

Karena sangat kompleknya persamaan di atas, parameter-parameter yang digunakan untuk $m=2,3,4,5$ dan 6 diberikan dalam tabel 2 berikut ini. Metode-metode tersebut semuanya memiliki orde-empat.

TABEL 2. Parameter-parameter hasil contoh 2

\begin{tabular}{ccccccc}
\hline$m$ & 2 & 2 & 3 & 4 & 5 & 6 \\
\hline$a$ & 1 & $\frac{4}{3}$ & $\frac{3}{2}$ & 2 & $\frac{5}{2}$ & 3 \\
$b$ & free & free & free & 2 & $\frac{5}{2}$ & 3 \\
$c$ & free & $\frac{1-b}{3}$ & $\frac{3}{5}-\frac{b}{4}$ & 0.064783 & 0.021737 & 0.008212 \\
$a_{1}$ & $-\frac{1}{2}$ & $\frac{1-2 b}{2}$ & $\frac{25}{108} b-\frac{43}{72}$ & -0.437458 & -0.430345 & -0.368149 \\
$a_{2}$ & 2 & $3(b-1)$ & $4-\frac{25}{72} b$ & 7.904129 & 18.815436 & 39.687683 \\
$a_{3}$ & 0 & 2 & $-\frac{125}{72}$ & -5.912818 & -15.894083 & -35.699379 \\
$r_{1}$ & $-\frac{1}{2}$ & $\frac{2}{9} b-\frac{13}{18}$ & $\frac{5 b}{1296}-\frac{37}{108}$ & -0.236261 & -0.164791 & -0.120179 \\
$r_{2}$ & $\frac{3}{8}$ & $\frac{7}{8}-\frac{b}{2}$ & $\frac{25}{81}-\frac{5 b}{972}$ & 0.154675 & 0.101387 & 0.073031 \\
$r_{3}$ & $\frac{1}{8}$ & $\frac{1}{8}$ & $\frac{2}{25}$ & 0.083527 & 0.069672 & 0.057025 \\
\hline
\end{tabular}

Batas kesalahan diberikan oleh

$$
e_{n+1}=\left(r_{1} B_{1} B_{2}+r_{2} B_{1}^{3}+r_{3} B_{3}\right) e_{n}^{4}
$$

Dimana $r_{1}, r_{2}$, dan $r_{3}$ adalah yang diberikan dalam table diatas untuk setiap $m$. Untuk $m=3$, dapat dipilih dengan parameter $b$ dengan bebas untuk menyamakn $a=\frac{3}{2}$.

Ringkasnya, dalam penelitian ini telah dihasilkan metode orde-empat yang menggunakan satu fungsi dan tiga turunan dalam setiap iterasi. Efisiensi informasi pada metode-metode tersebut adalah 1, seperti metode-metode yang telah disebutkan diatas untuk akar-akar yang banyak. Indeks efisiensinya adalah 1.4142 yang lebih rendah daripada metode-metode orde-tiga. Dalam hal $m=2$ diperoleh sebuah metode yang hanya memerlukan dua perhitungan turunan $\left(a_{3}=0\right)$ sehingga efisiensi informasinya adalah $4 / 3$ dan indeks efisiensinya adalah 1.5874 . 


\section{Simulasi Numerik}

Dalam contoh pertama ini digunakan sebuah polynomial kuadratik yang mempunyai dua akar pada $\xi=1$.

$$
f(x)=x^{2}-2 x+1
$$

Dalam contoh ini, dimulai dengan $x_{0}=0$, dan kekonvergenannya diperoleh dalam 1 iterasi. Dalam contoh kedua, diambil polynomial yang mempunyai dua akar pada $\xi= \pm 1$.

$$
f(x)=x^{4}-2 x^{2}+1
$$

Dimulai pada $x_{0}=0.8$, metode ini konvergen dalam 1 iterasi. Jika dimulai dengan $x_{0}=0.6$, metode ini memerlukan 2 kali iterasi. Hasil perhitungannya diberikan dalam table 1 .

Hasil yang sama juga diperoleh jika dimulai dengan $x_{0}=-0.8$ dan $x=-0.6$ untuk konvergen pada $\xi=-1$.

Contoh berikutnya adalah polinomial dengan 3 akar pada $\xi=1$.

$$
f(x)=x^{5}-8 x^{4}+24 x^{3}-34 x^{2}+23 x-6
$$

Iterasinya dimulai dengan $x_{0}=0$ dan hasilnya diringkas dalam tabel 3. Contoh lainnya dengan 2 akar pada $\xi=0$ adalah

$$
f(x)=x^{2} e^{x}
$$

Dimulai pada $x_{0}=0.1$ metode ini konvergen dalam 1 iterasi, tetapi jika nilai awalnya dimulai pada $x_{0}=0.2$, metode ini konvergen dalam 1 iterasi. Hasil perhitungannya diberikan dalam tabel 4 . Contoh terakhir adalah polinomial yang mempunyai akar ganda pada $\xi=1$

$$
f(x)=3 x^{4}+8 x^{3}-6 x^{2}-24 x+19
$$

TABEL 3. Hasil dari contoh 3

\begin{tabular}{ccc}
\hline$n$ & $x$ & $f$ \\
\hline 0 & 0 & -6 \\
1 & 0.95239072 & $-0.23148417(-3)$ \\
2 & 0.99999683 & $-0.63(-16)$ \\
\hline
\end{tabular}

TABEL 4. Hasil dari contoh 4

\begin{tabular}{ccccc}
\hline$n$ & $x$ & $f$ & $x$ & $f$ \\
\hline 0 & 0.1 & $0.11051709(-1)$ & 0.2 & $0.48856110(-1)$ \\
1 & $0.12654311(-4)$ & $0.16013361(-9)$ & $0.17709827(-3)$ & $0.31369352(-7)$ \\
2 & $0.3739(-20)$ & 0 & $0.14341725(-15)$ & 0 \\
\hline
\end{tabular}

TABEL 5. Hasil dari contoh 5

\begin{tabular}{ccc}
\hline$n$ & $x$ & $f$ \\
\hline 0 & 0 & 19 \\
1 & 1.46056319 & 9.725126111 \\
2 & 1.00101187 & $0.368806435(-4)$ \\
3 & 1 & 0 \\
\hline
\end{tabular}




\section{Daftar Pustaka}

Dong, C., (1987), A family of multipoint iterative function for finding multiple zeros of nonlinear equations, Int. J. Comput. Math., 21, pp 363-367

Halley, E., (1964), A New, Exact and Easy Method of Finding The Roots of Equations Generally and that without Any Previous Reduction., Phil. Trans. R. Soc. London, 18, pp 136-148.

Hansen, E., Patrick, M., (1977), A family of root finding methods, Numer. Math., 27, pp 257-269.

Jarrat, P., (1966), Some Fourth Order Multipoint Methods for Solving Equations, Math. Comp., 20, pp 434-437.

Jarrat, P., (1996), Multipoints Iterative Methods for Solving Certain Equations, Comput. $J ., 8$, pp 398-400.

King, R.F., (1973), A Family of Fourth Order Methods for Nonlinear Equations, SIAM J. Numer. Anal., 10, pp 876-879.

Neta, B., (1983), Numerical Methods for The Solution of Equations, Net-A-Sof, California.

Ostrowski, A.M., (1960), Solution of Equations and System of Equations, Academic Press, New York.

Rall, L.B., (1996), Convergence of The Newton Process to Multiple Solutions, Numer. Math., 9, pp 23-37.

Redfern, D., (1994), The Maple Handbook, Springer-Verlag, New York.

Schroder, E., (1996), Uber unendlich viele algorithm zur auflosung der gleichungen, Math. Ann., 2, pp 23-37.

Traub, J.F., (1964), Iterative Methods for the Soslution of Equations, Prentice Hall, New Jersey.

Victory, H.D., Neta, B., (1987), A higher order method for multiple roots of equations, Int. J. Comput. Math., 21, pp 363-367. 